\title{
Sifat histerisis pada konstanta dielektrik dan indeks bias minyak zaitun dengan variasi suhu
}

\author{
Bowo Eko Cahyono ${ }^{1}$, M. Misto ${ }^{1}$, Luluk Mukarromah ${ }^{1}$ \\ ${ }^{1}$ Jurusan Fisika, FMIPA, Universitas Jember, Jember 68121, Indonesia \\ E-mail: bowo_ec.fmipa@unej.ac.id; misto.fmipa@unej.ac.id,u2k_aidy@yahoo.co.id
}

Received: 2901 2018. Revised: 2304 2018. Accepted: 22052018

\begin{abstract}
Abstrak
Penelitian ini dilakukan untuk mengetahui karakteristik kurva histerisis melalui pengukuran konstanta dielektrik dan indeks bias. Kurva histerisis konstanta dielektrik digunakan untuk mengetahui karakteristik bahan dalam menyimpan energy listrik sementara kurva histerisis indeks bias dipakai untuk menggambarkan kemampuan bahan dalam menyimpan energy termal. Bahan yang diteliti berupa 3 jenis minyak zaitun. Penelitian ini menggunakan metode rangkaian kapasitif dan difraksi Fraunhofer celah ganda. Diketahui bahwa ketiga jenis minyak zaitun memiliki lebar kurva histerisis yang berbeda pada pengukuran konstanta dielektrik maupun indeks bias dengan variasi suhu. Hubungan antara nilai konstanta dielektrik terhadap suhu menunjukkan peningkatan, sedangkan untuk nilai indeks bias menunjukkan penurunan. Pada pengukuran konstanta dielektrik menunjukkan bahwa minyak zaitun virgin olive oil memiliki lebar kurva histerisis paling besar dibandingkan minyak zaitun extra virgin olive oil dan extra light olive oil, hal ini menunjukkan bahwa minyak zaitun virgin olive oil memiliki kemampuan paling besar untuk menyimpan enegi listrik. Sedangkan pada pengukuran indeks bias menunjukkan bahwa minyak zaitun extra virgin olive oil memiliki lebar kurva histerisis paling besar dibandingkan minyak zaitun extra light olive oil dan virgin olive oil. Hal ini juga menunjukkan bahwa minyak zaitun extra virgin olive oil memiliki kemampuan paling besar untuk menyimpan enegi termal.
\end{abstract}

Kata Kunci: minyak zaitun; konsanta dielektrik; indeks bias; kapasitif; difraksi; histerisis.

\section{Hysteresis Properties On The Dielectric Constant and Refractive Index of Olive Oil in The Temperature Variations}

\begin{abstract}
This research was conducted to find out the characteristics of the hysteresis curve through the measurement of dielectric constant and refractive index. The hysteresis curves of dielectric constant are used to know material properties to save electrical energy, while the hysteresis curves of refraction index are utilized to describe the ability of material in keeping thermal energy. The materials examined are 3 types of olive oil. This research method uses capasitive circuit and double slit Fraunhofer diffraction. The research results show that those three types of olive oil have different hysteresis curves in terms of relationship of temperature and dielectric constants as well as refractive index. The relationship between the dielectric constants values against temperature is proportional, while the values of refractive index are inversely proportional to the temperature. The measurement of the dielectric constant shows that virgin olive oil has a largest width of hysteresis curves than extra virgin olive oil and extra light olive oil. This suggests that virgin olive oil has the greatest ability to store electrical energy. Meanwhile, the measurement of the refractive index shows that extra virgin olive oil has largest width of hysteresis curves than extra light olive oil and virgin olive oil, it also showed that the extra virgin olive oil has the greatest ability to store thermal energy.
\end{abstract}

Keywords: olive oil; dielectric constants; refractive index; capacitive; diffraction; hysteresis 


\section{PENDAHULUAN}

Minyak zaitun berasal dari ekstrasi buah zaitun (olea suropaea). Minyak zaitun banyak mengandung asam lemak tak jenuh dan sumber polifenol. Tingginya asam lemak tak jenuh yang terkandung dalam minyak zaitun memberi manfaat yang sangat baik untuk tubuh yaitu, dalam bidang kesehatan, kecantikan, dan dalam pencegahan penyakit (Fajriyah et. al., 2015) serta dapat digunakan untuk memasak makanan untuk mencegah kolesterol (Handayani et. al., 2011). Minyak zaitun yang dipanaskan akan menyebabkan perubahan komposisi asam lemak. Perubahan ini terjadi karena adanya minyak yang teroksidasi oleh oksigen. Oksidasi menyebabkan jumlah asam lemak tak jenuh dalam minyak zaitun menurun sehingga mempengaruhi kualitas minyak zaitun (Rofiq, 2010).

Minyak zaitun juga memiliki beberapa sifat sebagai bahan, diantaranya sifat listrik dan sifat optik. Sifat listrik berkaitan dengan konduktivitas listrik, resistivitas listrik dan konstanta dielektrik yang diperoleh dengan memberikan stimulus berupa medan listrik (Kamajaya, 1984). Sedangkan Sifat optik menggambarkan bagaimana respon suatu material terhadap medan elektromagnetik atau radiasi cahaya. Sifat optik ini bisa direpresentasikan pada nilai indeks biasnya (Rofiq, 2010).

Sifat listrik suatu bahan berhubungan dengan resistansi, konduktansi, induktansi dan kapasitansi (Rochdi et. al., 2014). Kapasitansi suatu bahan merupakan kemampuan bahan tersebut dalam menyimpan muatan listrik (Tipler \& Mosca, 2008) dan sifat bahan yang berkaitan dengan nilai kapasitansinya dikenal dengan istilah sifat kapasitif.(Giancoli, 2011). Sifat kapasitif ini dapat diidentifikasi dari nilai konstanta dielektriknya. Semakin tinggi nilai konstanta dielektrik suatu bahan maka semakin besar kemampuan bahan tersebut untukmenyimpan energi listrik dalam bentuk muatan listrik. .

Sementara itu sifat optik suatu bahan juga dapat dilihat berdasarkan kurva histerisis, dimana kurva histerisis tersebut mampu menjelaskan seberapa besar energi yang masih tetap disimpan di dalam bahan akibat energi masukan yang diterapkan pada bahan tersebut. Histerisis merupakan sifat yang dimiliki oleh suatu bahan, dimana bahan tersebut tidak secara cepat merespon gaya yang diberikan kepadanya, tetapi memberikan reaksi secara perlahan atau bahkan keadaan bahan tidak kembali lagi ke keadaan awalnya (Moris, 2001).

Berdasarkan penjelasan di atas, kami melakukan penelitian mengenai karakteristik listrik dan karakteristik optik suatu bahan. Tujuan dari penelitian ini adalah untuk mengetahui lebar kurva histerisis yang dihasilkan pada pengukuran konstanta dielektrik dan indeks bias. Penelitian ini menggunakan metode kapasitif dan metode difraksi Fraunhofer celah ganda.

Konstanta dielektrik adalah suatu konstanta yang besarnya tergantung pada sistem yang digunakan serta bahan yang digunakan. Sedangkan sistem yang digunakan adalah nilai kapasitor yang dibentuk dari dua buah pelat sejajar yang dipisahkan oleh bahan dielektrik (Kamajaya, 1984).

Secara praktis, sifat dielektrik sering dikaitkan dengan kelistrikan bahan isolator yang ditempatkan di antara dua keping kapasitor (Sutrisno, 1985). Konstruksi dari suatu kapasitor secara sederhana adalah dua elektroda pelat sejajar yang dipisahkan oleh dielektrik, atau secara umum disebut sebagai kapasitor pelat sejajar seperti yang ditunjukan pada gambar di bawah ini.

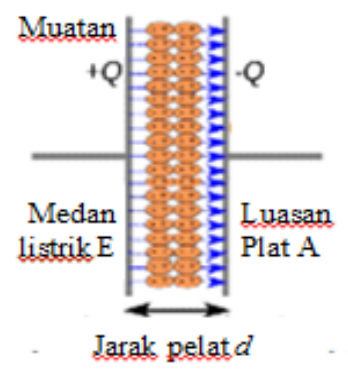

Gambar 1. Kapasitor Pelat Sejajar (Tipler \& Mosca, 2008).

Apabila kapasitor pelat sejajar dengan luas penampang (A) dipisahkan oleh dielektrik dengan jarak (d), kemudian pelat tersebut diberi tegangan $(\mathrm{V})$, maka akan timbul medan listrik (E) yang bekerja di dalam listrik. Akibat adanya medan listrik, maka muatan yang terkandung di dalam dielektrik akan terpolarisasi (Umar, 2008). 


\section{Jurnal Pendidikan Fisika dan Keilmuan (JPFK), 4 (2), 2018 - 50}

Bowo Eko Cahyono, M. Misto, Luluk Mukaromah

Untuk sebuah kapasitor pelat sejajar, nilai kapasitansi dapat dituliskan persamaan:

$$
C=\frac{\varepsilon_{0} A}{d}
$$

Konstanta dielektrik dinyatakan dalam:

$$
\varepsilon_{y}=C \frac{d}{\varepsilon_{\sigma} A}
$$

Keterangan :

$$
\begin{array}{ll}
\varepsilon_{y} & : \text { Konstanta Dielektrik } \\
C & : \text { Kapasitansi minyak }(p F) \\
\varepsilon_{0} & : \text { Permitivitas ruang hampa } \\
A & : \text { Luas Tembaga }\left(\mathrm{m}^{2}\right) \\
d & : \text { Jarak plat }(\mathrm{m})
\end{array}
$$

Indeks bias pada setiap medium optik dinyatakan sebagai suatu perbandingan antara cepat rambat cahaya di dalam ruang hampa (vakum) dan cepat rambat cahaya di dalam medium. Secara matematis, indeks bias dinyatakan sesuai persamaan :

$$
n=\frac{e}{v}
$$

Keterangan:

$n$ = indeks bias

$c=$ kecepatan cahaya di dalam vakum $\left(\mathrm{m} / \mathrm{s}^{2}\right)$

$v=$ kecepatan cahaya di dalam medium $\left(\mathrm{m} / \mathrm{s}^{2}\right)$

Difraksi merupakan suatu fenomena setiap simpangan dari optik geometri yang dihasilkan dari gangguan muka gelombang cahaya (Pedrotti \& Pedrotti, 1993). Nilai indeks bias larutan dapat dianalisis menggunakan metode difraksi Fraunhofer celah ganda, dengan membandingkan nilai simpangan pola difraksi pada dua medium yang berbeda, sesuai dengan gambar di bawah (Nemoto, 1992):

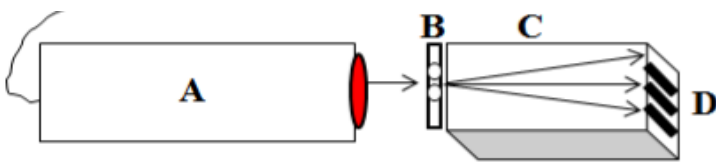

Gambar 2. Berkas sinar laser yang melewati medium udara dan larutan sukrosa (Nemoto, 1992)

Keterangan:

$\mathrm{A}=$ Laser $\mathrm{HeNe}$

$\mathrm{B}=$ Holder celah ganda

$\mathrm{C}=$ Minyak zaitun dalam wadah sampel

$\mathrm{D}$ = Pola difraksi layar pengamatan

Secara matematis, nilai indeks bias dengan menggunakan metode Franhoufer dapat dituliskan dengan persamaan (4) berikut ini (Fendley, 1982):

$$
n=\frac{c}{W}=\frac{\lambda_{1}}{\lambda_{2}}=\frac{x_{1}}{x_{2}}
$$

Keterangan:

$\lambda_{I}=$ panjang gelombang sumber pada medium udara $(\mathrm{nm})$

$\lambda_{2}=$ panjang gelombang sumber pada medium larutan $(\mathrm{nm})$

$x_{I}=$ simpangan pola difraksi pada medium udara (m)

$x_{2}=$ simpangan pola difraksi pada medium larutan (m)

Karakteristik sifat listrik dan sifat optik suatu bahan juga dapat dilihat berdasarkan kurva histerisis. Histerisis merupakan sifat yang dimiliki oleh suatu bahan dimana bahan tersebut tidak secara cepat merespon gaya yang diberikan kepadanya, tetapi memberikan reaksi secara perlahan atau bahkan keadaan bahan tidak kembali ke keadaan awal.

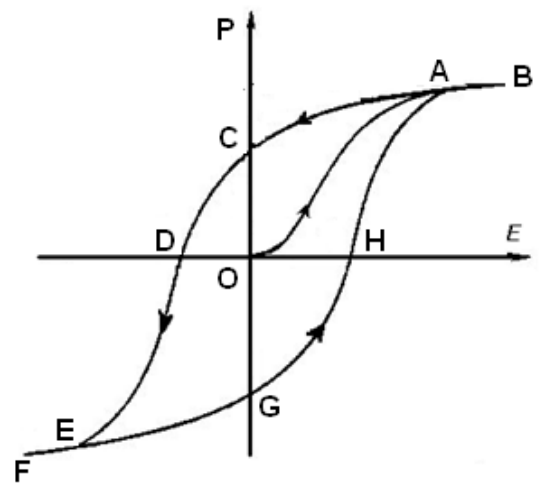

Gambar 3. Kurva histerisis medan listrik eksternal $(E)$ - polarisasi $(P)$ (Istiqomah et. al., 2014)

Berdasarkan gambar 3, apabila kuat medan listrik $(E)$ ditingkatkan maka polarisasi $(P)$ akan meningkat mengikuti garis $O A$, hingga akhirnya konstan seperti garis $A B$ (keadaan saturasi). Kemudian, apabila kuat medan listrik $(E)$ diturunkan hingga titik $O$, maka polarisasi $(P)$ akan mengikuti garis $B C$, bukan kembali lagi ke titik $O$. Hal ini menunjukkan bahwa masih terdapat sisa polarisasi di dalam bahan ketika medan listrik dihilangkan (Ripka \& Tipek, 2007). Sisa polarisasi ini disebut dengan polarisasi remanan. Adanya sisa polarisasi tersebut menunjukkan terdapat sebagian energi yang tetap tersimpan di dalam bahan. Semakin besar sisa polarisasi menunjukkan semakin lebar kurva histerisis sehingga energi yang tersimpan semakin besar. 


\section{METODE}

Beberapa peralatan yang digunakan dalam penelitian ini adalah laser $\mathrm{He}-\mathrm{Ne}(\lambda=$ $632,8 \mathrm{~nm}$ ), celah difraksi celah ganda dengan lebar celah 0,04 milimeter, layar pengamatan, wadah transparan dengan dimensi $7,5 \mathrm{~cm} \mathrm{x}$ $2,5 \mathrm{~cm} \times 5 \mathrm{~cm}$ dan tebal $1 \mathrm{~mm}$, bangku laser (OS-9172), stavol, jangka sorong, kapasitansimeter, termometer, elemen pemanas, sumber tegangan 36 volt, dan tembaga. Variasi perlakuan suhu yang digunakan adalah suhu $30^{\circ} \mathrm{C}$ sampai suhu $60^{\circ} \mathrm{C}$, kemudian diturunkan kembali dari suhu $60^{\circ} \mathrm{C}$ sampai $30^{\circ} \mathrm{C}$ dengan interval setiap kenaikan $5^{\circ} \mathrm{C}$.

Bahan yang digunakan adalah 3 jenis minyak zaitun yaitu extra virgin olive oil, virgin olive oil, extra light olive oil, dan aquades sebagai bahan pelarut sampel. Pengukuran konstanta dielektrik pada minyak zaitun dilakukan dengan menggunakan metode kapasitif dan pengukuran indeks bias dilakukan dengan menggunakan metode difraksi Fraunhofer celah ganda.

Desain rangkain alat pengukuran konstanta dielektrik dan indeks bias minyak zaitun ditunjukkan oleh gambar dibawah ini:

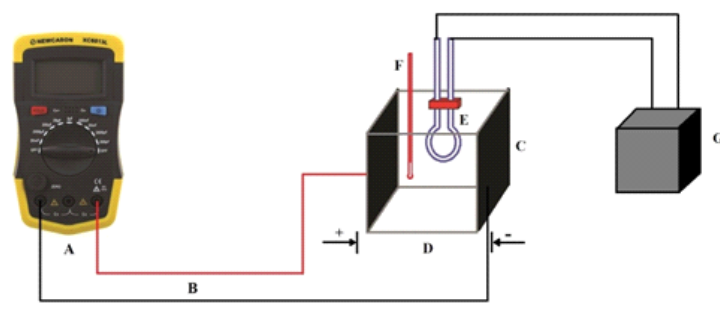

Gambar 4. Rancangan alat penelitian konstanta dielektrik

Keterangan:

A : Kapasitansimeter (CM8601A);

B : Kabel;

C : Plat PCB (Printed Circuit Board);

$\mathrm{D}$ : Wadah minyak zaitun;

E : Elemen pemanas;

F : Termometer digital;

$\mathrm{G}$ : Sumber tegangan 36 volt.

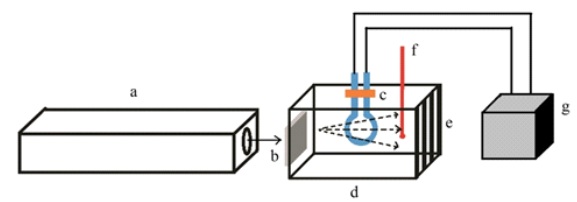

Gambar 5. Rancangan alat penelitian indeks bias

Keterangan:

a : Laser $\mathrm{HeNe}(\lambda=632,8 \mathrm{~nm})$;

$\mathrm{b}$ : Kisi celah ganda;

$c$ : Elemen pemanas;

$\mathrm{d}$ : Wadah transparan untuk minyak zaitun;

e : Layar pengamatan;

$\mathrm{f}:$ Termometer digital;

$\mathrm{g}:$ Sumber tegangan 36 volt.

Kalibrasi pada kapasitansimeter maupun difraksi Fraunhofer celah ganda dilakukan sebelum alat digunakan untuk penelitian. Kalibrasi pada kedua alat ini menggunakan sampel larutan aquades dan didapatkan nilai konstanta dielektrik 78 dan nilai indeks bias 1,31. Berdasarkan nilai kalibrasi yang didapatkan pada kedua alat yang dibandingkan dengan referensi, maka alat telah sesuai dan layak untuk digunakan.

Analisis nilai konstanta dielektrik didapatkan dengan menentukan nilai kapasitansi dai minyak zaitun, kemudian nilai kapasitansi yang didapat digunakan untuk menghitung nilai konstanta dielektrik minyak zaitun, seperti pada pesamaan (2). Sedangkan analisis nilai indeks bias didapatkan dengan membandingkan simpangan pola difraksi yang ditangkap oleh layar yang melewati medium udara dan medium minyak zaitun, seperti pada persamaan (4) sebelumnya.

Nilai konstanta dielektrik $\left(\varepsilon_{\mathrm{r}}\right)$ dan nilai indeks bias $(n)$ pada mintyak zaitun selanjutnya digunakan untuk mengetahui karakteristik histerisis konstanta dielektrik minyak zaitun dengan membuat grafik hubungan nilai konstanta dielektrik dan indeks bias terukur terhadap suhu yang diukur mulai dari suhu yang terendah sampai suhu tertinggi. Kemudian pengukuran yang sama dilakukan dari suhu yang tinggi ke suhu yang rendah dengan nilai atau cara yang sama. Kemudian dari kurva hubungan konstanta dielektrik dan indeks bias terhadap suhu dihitung lebar kurva histerisis dari ketiga jenis minyak zaitun melalui selisih 
konstanta dielektrik dan indeks bias yang dihasilkan pada suhu yang sama. Setelah lebar kurva histerisis dari ketiga jenis minyak zaitun diketahui, maka dapat disimpulkan mana minyak yang memiliki lebar kurva histerisis yang paling lebar.

\section{HASIL DAN PEMBAHASAN}

Data yang diperoleh pada penelitian ini adalah nilai kapasitansi dan pola difraksi minyak zaitun pada setiap variasi suhu. Nilai kapasitansi yang diperoleh dapat digunakan untuk mengetahui nilai konstanta dielektrik dari minyak zaitun, sedangkan pola difraksi dapat digunakan untuk mengetahui nilai indeks bias dari minyak zaitun.

Data yang dihasilkan dari pengukuran, menunjukkan bahwa nilai konstanta dielektrik pada minyak zaitun semakin besar ketika suhu juga semakin besar seperti terlihat pada Gambar 6 sampai Gambar 8, Hal ini dikarenakan suhu yang semakin tinggi menyebabkan molekul- molekul merenggang dan muatan pada minyak zaitun dapat bergerak menjadi lebih bebas. Molekul yang merenggang mengakibatkan muatan bahan lebih mudah terpolarisasi. Kemudahan terpolarisasi ini berhubungan dengan meningkatnya nilai konstanta dielektrik. Semakin mudah suatu bahan dielektrik terpolarisasi maka akan semakin tinggi nilai konstanta dielektriknya. Inilah alasan mengapa dengan semakin meningkatnya suhu maka data nilai konstanta dielektrik yang diperoleh juga semakin meningkat pula (Drnevich et. al., 2002).

Dari 3 jenis minyak zaitun yang diteliti, ada respon yang berbeda dalam hal nilai konstanta dielektrik yang berhubungan dengan variasi suhu yang diberikan seperti ditunjukkan pada gambar 6 sampai gambar 8 .

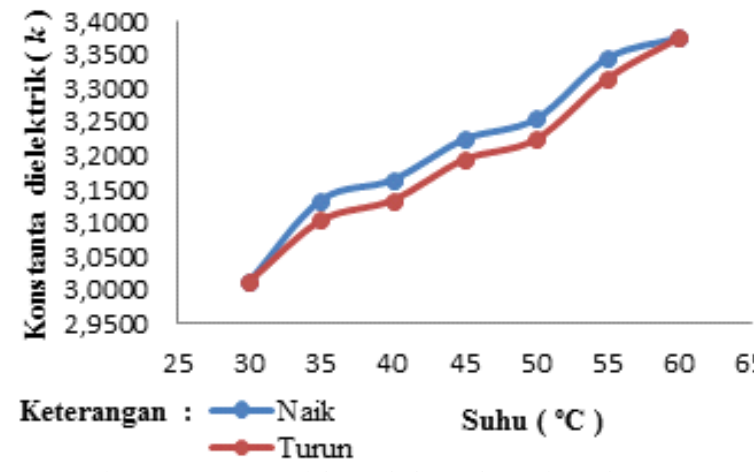

Gambar 6. Kurva histerisis minyak zaitun extra light olive oil pada pengukuran konstanta dielektrik

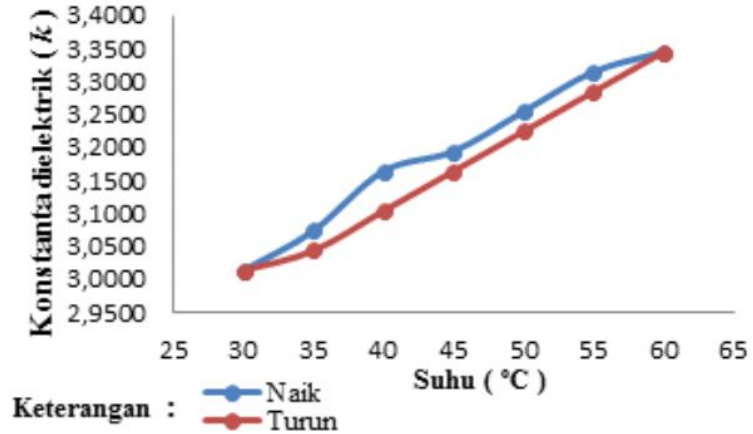

Gambar 7. Kurva histerisis minyak zaitun extra virgin olive oil pada pengukuran konstanta dielektrik

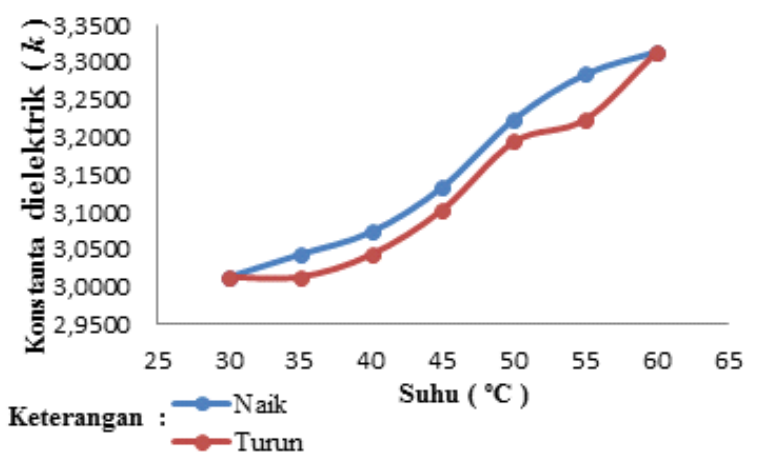

Gambar 8. Kurva histerisis minyak zaitun virgin olive oil pada pengukuran konstanta dielektrik

Berdasarkan grafik pada gambar 6, gambar 7, dan gambar 8, terlihat adanya pola kurva histerisis pada hubungan antara variasi suhu yang diberikan pada minyak zaitun dengan nilai konstanta dielektriknya. Minyak zaitun virgin olive oil memiliki lebar kurva histerisis paling besar dengan nilai lebar kurva maksimum sebesar 0,0603 yang diperoleh pada suhu $55^{\circ} \mathrm{C}$. Sedangkan untuk minyak zaitun extra virgin olive oil memiliki lebar kurva histerisis lebih kecil daripada minyak zaitun virgin olive oil yaitu sebesar 0,0602 pada suhu $40^{\circ} \mathrm{C}$. Untuk minyak zaitun extra light olive oil memiliki lebar kurva histerisis yang paling kecil dengan nilai 0,0301 . Hal ini menunjukkan bahwa minyak zaitun virgin olive oil memiliki kemampuan paling besar untuk menyimpan energi listrik, sedangkan pada minyak zaitun extra light olive oil memiliki kemampuan paling kecil ${ }_{5}$ untuk menyimpan energi listrik.

Selanjutnya penelitian juga dilakukan untuk mengetahui karakteristik indeks bias minyak zaitun terhadap variasi perubahan suhunya. Data hasil penelitian menunjukkan bahwa nilai indeks bias pada minyak zaitun 
akan semakin kecil seiring dengan meningkatnya suhu minyak zaitun. Hasil ini serupa dengan hasil penelitian sebelumnya yang dilakukan oleh Waxler dan Cleek (1973). Hal ini dikarenakan ketika suhu minyak zaitun dinaikkan maka akan menyebabkan ikatan karbon pada molekul minyak mudah rusak atau pecah (Yusim, 2011). Akibat lain yang timbul adalah rantai karbon pada senyawa minyak tersebut akan menjadi lebih pendek., Memendeknya rantai karbon pada senyawa minyak zaitun berdampak pada menurunnya nilai kerapatan optis minyak. Secara fisis, kerapatan optis ini berbanding lurus dengan indeks bias (Serway \& Jewett, 2010) sehingga menurunnya kerapatan optis juga mengakibatkan menurunnya indeks bias. Hubungan antara nilai indeks bias terukur dengan variasi suhu yang diberikan pada minyak zaitun dapat dilihat pada gambar 9 sampai dengan gambar 11 berikut.

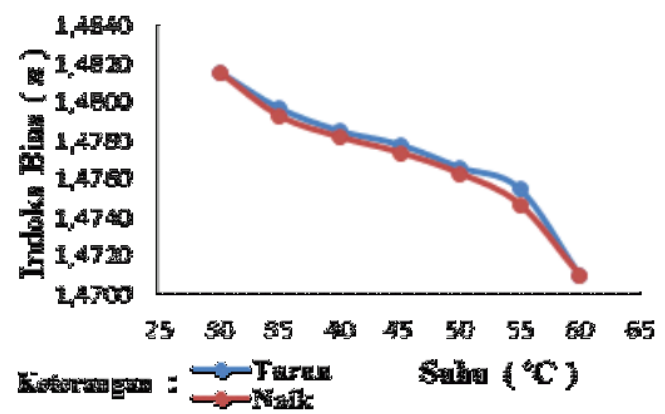

Gambar 9. Kurva histerisis minyak zaitun extra light olive oil pada pengukuran indeks bias

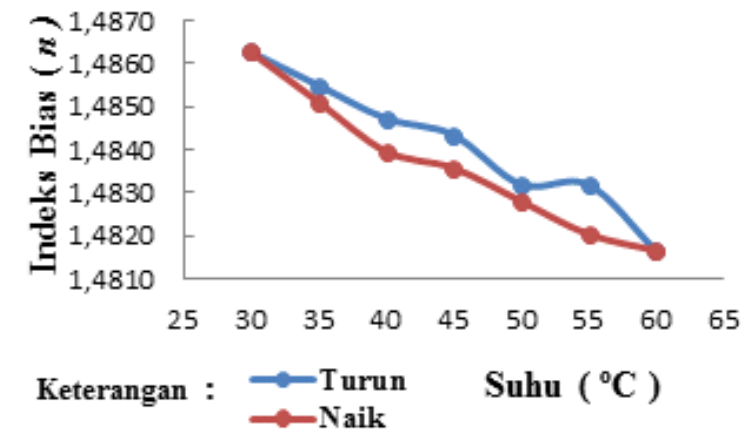

Gambar 10. Kurva histerisis minyak zaitun extra virgin olive oil pada pengukuran indeks bias

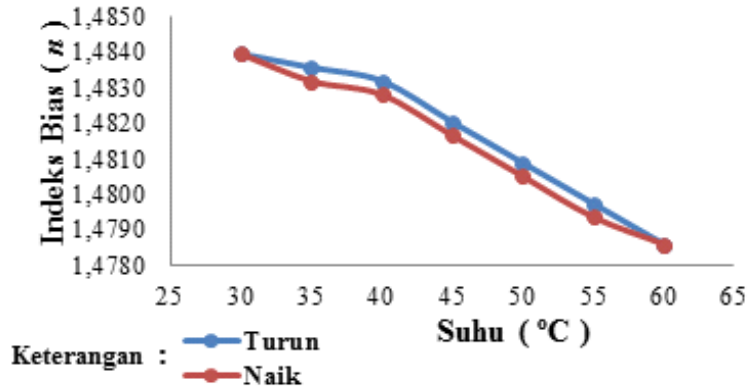

Gambar 11. Kurva histerisis minyak zaitun virgin olive oil pada pengukuran indeks bias

Berdasarkan hasil yang ditunjukkan pada gambar 9, gambar 10, dan gambar 11 diketahui bahwa ketiga jenis minyak zaitun yang digunakan memiliki karakterisis histerisis pada kurva hubungan antara nilai indeks bias dan temperaturnya. Dari kurva karakteristik tersebut dapat diamati bahwa ketika suhu dinaikkan maka nilai indeks bias akan turun dan sebaliknya ketika suhu diturunkan maka nilai indeks bias akan naik tetapi lintasan kurvanya berada di bawah kurva lintasan penurunan nilai indeks bias ketika suhunya dinaikkan. Atau dengan kata lain ada histerisis pada kurva hubungan nilai indeks bias dan perubahan suhu pada minyak zaitun. Hal ini mengindikasikan bahwa ketika suhu diturunkan, olive oil masih menyimpan energi termal dan penurunan kerapatan optisnya dan juga penurunan nilai indeks biasnya sedikit tertinggal daripada penurunan suhunya. Semakin lebar kurva histerisisnya maka kita dapat mengatakan bahwa bahan tersebut memiliki kemampuan menyimpan energi termal yang semakin baik.

Berdasarkan kurva histerisis hubungan indeks bias dan temperature, posisi dan lebar kurva histerisis dari masing-masing jenis minyak zaitun menunjukkan pola yang berbeda. Pada minyak zaitun jenis extra virgin olive oil lebar kurva histerisis yang dihasilkan paling besar dengan lebar kurva maksimum berada pada suhu $55^{\circ} \mathrm{C}$ dengan nilai 0,0012 . Sedangkan untuk minyak zaitun jenis extra light olive oil memiliki lebar kurva histerisis lebih kecil daripada minyak zaitun extra virgin olive oil yaitu sebesar 0,0008 berada pada suhu $55^{\circ} \mathrm{C}$. Untuk minyak zaitun virgin olive oil memiliki lebar kurva histerisis yang paling kecil dengan nilai 0,0004 . Hal ini menunjukkan bahwa minyak zaitun jenis extra virgin olive oil memiliki kemampuan menyimpan energi termal paling besar, dan minyak zaitun jenis 
extra light olive oil memiliki kemampuan menyimpan energi termal yang lebih besar dibandingkan minyak zaitun virgin olive oil. Sedangkan untuk minyak zaitun virgin olive oil sendiri memiliki kemampuan menyimpan energi termal paling kecil.

\section{SIMPULAN}

Berdasarkan penelitian yang telah dilakukan, didapatkan kesimpulan:

1. Kurva histerisis diperoleh dari hubungan konstanta dielektrik terhadap variasi suhu dan indeks bias.

2. Kurva histerisis konstanta dielektrik terhadap suhu menunjukkan bahwa virgin olive oil memiliki lebar paling besar dibandingkan extra-virgin olive oil dan extra light olive oil.

Kurva histerisis indeks bias terhadap suhu menunjukkan bahwa extra-virgin olive oil memiliki lebar paling besar dibandingkan extra light olive oil dan virgin olive oil.

\section{DAFTAR PUSTAKA}

Drnevich, V. P., Yu, X., Lovell, J. \& Tishmack, J. (2002). Temperature Effects On Dielectric Constant Determined By Time Domain Reflectometry. West Lafayette - India: School of Civil Engineering, Purdue University.

Fajriyah, N. N., Andriani, A. \& Fatmawati (2015). Efektivitas Minyak Zaitun untuk Pencegahan Kerusakan Kulit pada Pasien Kusta. Jurnal Ilmiah Kesehatan (JIK) 7 (1): 1-5.

Fendley, J. J. (1982). Measurement of refractive index using a Michelson interferometer. Physics Education 17: 209-211.

Giancoli, D. C. (2011). Fisika Jilid 2 Edisi Kelima. [diterjemahkan Dra. Yuhliza Hanum, M. Eng]. Jakarta Erlangga:

Dinas Kesehatan Provinsi NTB (2011). Pengaruh Suplementasi Minyak Zaitun Extra Virgin Terhadap Kolesterol Total Danntrigliserida Subjek Hiperkolesterolemia. Lombok: Dinas Kesehatan Provinsi NTB.

Istiqomah, M., Jamaluddin, A. \& Iriani, Y. (2014). Pembuatan Material Feroelektrik Barium Titanat (BaTiO3) Menggunakan Metode Solid State
Reaction. Jurnal Fisika Indonesia 18 (53): 59-61.

Kamajaya (1984). Ringkasan Fisika. 1 Ed. Bandung: Ganeca Exact Bandung:

Moris, A. S. (2001). Measurement and Instrumentation Principles. New Delhi: Butterworth:

Nemoto, S. (1992). Measurement of the refractive index of liquid using laser beam displacement. Applied Optics 31 (31): 6690-6694.

Pedrotti, F. J. \& Pedrotti, L. S. (1993). Introduction to Optics. New Jersey: Prentice Hall Inc.:

Ripka, P. \& Tipek, A. (2007). Modern Sensors Handbook : Instrumentation and Measurement Series. California USA: ISTE:

Rochdi, R., Lakrari, K., Hassanain, I., Alaoui, S. I., Belgharza, M., Elmakhoukhi, F., Azzouzi, E. H. E. \& Belghit, M. A. E. (2014). Study of The Electrical Properties of Vegetable Oils As An Alternative To Mineral Insulating Oils. Advances in Environmental Biology 8 (5): 1218-1221.

Rofiq, A. (2010). Analisa Indeks Bias pada Pengukuran Konsentrasi Larutan Sukrosa Menggunakan Portable Brix Meter. Skripsi, Semarang, Jurusan Fisika - FMIPA, Universitas Diponegoro.

Serway, R. A. \& Jewett, J. W. (2010). Physics for Scientists and Engineers with Modern Physics $8^{\text {th }}$ edition. Belmont-USA: Brooks/Cole:

Sutrisno (1985). Elektronika Teori dan Penerapannya. Bandung: ITB Press:

Tipler, P. A. \& Mosca, G. (2008). Physics for Scientist and Engineers. $6^{\text {th }} \mathrm{Ed}$. New York: W.H. Freeman and Company:

Umar, E. (2008). Buku Pintar Fisika. Jakarta: Media Posindo:

Waxler, R. M. \& Cleek, G. W. (1973). The EHect of Temperature and Pressure on the Refractive Index of Some Oxide Glasses. JOURNAL OF RESEARCH of the National Bureau of Standards - A. Physics and Chemistry 77 A (6): 755763.

Yusim, V. (2011). Olive Oil Chemistry. http://veeveeayusim.blogspot.co.id/2011 /09/olive-oil-chemistry.html. [Diakses pada: 5 Januari 2017]. 